\title{
La necesaria transformación del modelo productivo en España: el papel del territorio*
}

\author{
Montserrat Pareja-Eastaway \\ Joaquin Turmo Garuz \\ GRC Creativitat, Innovació i Transformació Urbana \\ Universitat de Barcelona. Facultat d'Economia i Empresa \\ mpareja@ub.edu \\ jturmo@ub.edu
}

\section{Resumen}

El fracaso de las bases del modelo productivo español fundamentado en una baja productividad se ha traducido en una incapacidad absoluta de reacción frente a la crisis económica con crecientes tasas de paro y un grave estancamiento del PIB. El principal reto de la economía española requiere de apuestas decididas por pilares en los que se sustente un nuevo modelo productivo, esto es, la creatividad, la innovación y el conocimiento. Este artículo abordará en primer lugar el marco teórico en el que se enmarca el papel que asume el territorio en el siglo XXI como motor de cambio económico. Seguidamente, se identificarán los aspectos clave del actual modelo productivo y, a continuación, se estudiará la contribución del territorio al cambio de modelo sobre la base de cuatro grandes áreas metropolitanas: Madrid, Barcelona, Valencia y Bilbao. Finalmente, se incidirá en las recomendaciones de política pública a la luz de los anteriores resultados.

Palabras clave: modelo productivo; productividad; creatividad; conocimiento; territorio.

\section{Resum. La necessària transformació del model productiu a Espanya: el paper del territori}

El fracàs de les bases del model productiu espanyol fonamentat en una baixa productivitat s'ha traduït en una incapacitat absoluta de reacció davant la crisi econòmica amb creixents taxes d'atur i un greu estancament del PIB. El repte principal de l'economia

* Este artículo ha sido posible gracias a la financiación obtenida por el Ministerio de Economía y Competitividad, Proyectos de Investigación Fundamental no Orientada (2010-2012), Proyecto CREAURBS. Creatividad y conocimiento: Bases para una nueva competitividad urbana CSO2009-13137.

Este trabajo se inscribe en la investigación financiada con una ayuda para acciones de cooperación en el marco de la Comunitat de Treball dels Pirineus AC065723 (2010 XI-CTP) de la Agència de Gestió d'Ajuts Universitaris i de Recerca de la Generalitat de Catalunya; la Acción Complementaria (CS 02011-13651-E) del Ministerio de Ciencia e Innovación, y el subprograma Ramón y Cajal del Ministerio de Ciencia e Innovación (RYC-2008-02456). 
espanyola requereix apostes decidides per pilars en els quals se sustenti un nou model productiu, això és, la creativitat, la innovació i el coneixement. Aquest article abordarà en primer lloc el marc teòric en el qual s'emmarca el paper que assumeix el territori al segle XXI com a motor de canvi econòmic. Seguidament, s'identificaran els aspectes clau del model productiu actual i, a continuació, s'estudiarà la contribució del territori al canvi de model sobre la base de quatre grans àrees metropolitanes: Madrid, Barcelona, València i Bilbao. Finalment, s'incidirà en les recomanacions de política pública tenint en compte els resultats anteriors.

Paraules clau: model productiu; productivitat; creativitat; coneixement; territori.

Résumé. La transformation nécessaire du modèle de production en Espagne : le rôle du territoire

L'échec des fondements de modèle de production espagnol, basé sur une faible productivité a entraîné une incapacité totale à réagir à la crise économique avec des taux de chômage en hausse et une stagnation du PIB grave. Le principal défi de l'économie espagnole exige des actions décidées sur les piliers qui soutiennent un nouveau modèle de production, qui est, de la créativité, l'innovation et la connaissance. Cet article va discuter d'abord le cadre théorique qui correspond le rôle assumé par le territoire dans le XXIe siècle en tant que moteur du changement économique. Ensuite, identifier les aspects clés du modèle de production actuel, puis d'examiner la contribution du territoire de changer de modèle basé sur quatre grandes régions métropolitaines: Madrid, Barcelone, Valence et Bilbao. Enfin, nous aborderons les recommandations de politique publique à la lumière des résultats ci-dessus.

Mots clé: modèle de production; productivité; créativité; connaissance; territoire.

\section{Abstract. The need of transformation in the productive model in Spain: the role of territory}

The failure of the foundations of the Spanish production model based on low productivity has resulted in a complete inability to react to the economic crisis with rising unemployment rates and a serious stagnation of GDP. The main challenge of the Spanish economy requires of a decided bet for pillars in which a new production model would be sustained, that is, creativity, innovation and knowledge. This article will discuss first the theoretical framework that analyses the role assumed by the territory in the XXI century as an engine of economic change. Next, it will identify the key aspects of the current production model and then examine the contribution of the territory to change of model based on four major metropolitan areas: Madrid, Barcelona, Valencia and Bilbao. Finally, we will address the public policy recommendations under the light of the previous results.

Keywords: productive model; productivity; creativity; knowledge; territory.

\section{Sumario}

\section{Introducción}

2. Actividad económica y territorio: factores de localización

3. El modelo productivo de la economía española: productividad, empleo y capital
4. La dimensión territorial y el modelo productivo en España: el caso de Barcelona, Bilbao, Madrid y Valencia

5. Conclusiones

Referencias bibliográficas

Anexos 


\section{Introducción}

Los modelos productivos tradicionales basados en ventajas comparativas en costes o en sectores con un gran efecto de arrastre pero poco valor añadido han dejado de ser la vía competitiva para la mayoría de países. La transformación de la actividad económica que comporta la globalización reconoce como uno de los fenómenos más evidentes la primacía de sectores que incorporan un alto valor añadido procedente de la creatividad, el conocimiento y la innovación (Simmie, 2001; Lever, 2002). La capacidad de los países para adaptarse a un nuevo entorno depende, en buena parte, de su trayectoria económica, su especialización sectorial y la productividad de los factores de producción. En este contexto, las ciudades y sus entornos metropolitanos se enfrentan a nuevos parámetros competitivos que las obligan a replantear estrategias tradicionales de pervivencia en el panorama internacional.

Las aglomeraciones urbanas constituyen el núcleo en el que se desarrolla la mayor parte de la actividad económica. Dicha actividad se concentra en torno a grandes regiones metropolitanas de estructura diversa. La economía y el entorno urbano de las regiones metropolitanas están en continuo cambio y transformación (Scott y Storper, 2003). El resultado de dicha transformación ha sido la evolución de las ciudades, tradicionales centros de desarrollo industrial manufacturero, hacia las regiones metropolitanas postindustriales de comienzos del siglo XXI. Este proceso de transición hacia la ciudad-región postindustrial se acentuó a partir de los años setenta, cuando se hizo patente el cambio técnico y el abandono del fordismo.

La globalización de todos los ámbitos de la realidad, particularmente de los ámbitos económico, tecnológico y cultural, ha modificado la realidad de las ciudades y regiones urbanas. Sin embargo, la globalización no ha restado importancia al aspecto local del desarrollo; por el contrario, la globalización ha potenciado la atracción de las economías de aglomeración (Krugman, 1991; Feldman, 2000). Esto ha puesto de manifiesto los aspectos geográficos y la importancia de las regiones urbanas como núcleos de desarrollo de actividad y nodos de redes de ámbito internacional.

En esta nueva realidad, la competitividad, entendida como la capacidad de generar crecimiento económico, sigue siendo el objetivo perseguido por las regiones metropolitanas, aunque a través de nuevas actividades. De forma creciente, además de la acumulación de capital, la capacidad creativa de innovación de la sociedad tiene cada vez mayor importancia en la consecución del objetivo de la creación de riqueza (Jacobs, 1984; Bontje et al., 2011).

España es uno de los países más negativamente afectados por la crisis económica. Las altas tasas de paro y las dificultades en conseguir remontar el crecimiento del PIB ponen de manifiesto, una vez más, la obsolescencia de nuestro modelo económico y la necesidad de recomponer el tejido productivo del país sobre la base de nuevos pilares de crecimiento, a saber, la creatividad, el conocimiento y la innovación. La dimensión macroeconómica afecta directamente a la dimensión local o territorial. De este modo, el papel del territorio 
surge como crucial en la asunción de nuevas pautas de competitividad: en las ciudades se encuentra el origen del cambio económico y social de un país (Cooke y Simmie, 2005).

Este artículo pretende dar respuesta a las siguientes preguntas: idónde se encuentra la debilidad del actual modelo productivo en España? ¿Hasta qué punto el territorio y las aglomeraciones urbanas representan los motores dinámicos del cambio de modelo productivo? ¿Qué valor añadido proporciona el territorio en este necesario cambio de paradigma? En primer lugar, se abordará el estado de la cuestión en la literatura académica acerca de los cambios en el contexto global y su implicación en los requerimientos para la competitividad de un país. Se hará un particular hincapié en el papel del territorio en el siglo XXI como motor de atracción de actividad económica y crecimiento. Seguidamente, se identificarán los aspectos clave del actual modelo productivo en España y se valorará la contribución del territorio al cambio de este modelo sobre la base de cuatro grandes ciudades-región metropolitanas: Madrid, Barcelona, Valencia y Bilbao. Finalmente, se plantearán los ejes de cambio para la necesaria transformación del modelo productivo en España a partir de la capacidad del territorio para ejercer como motor de innovación y conocimiento.

\section{Actividad económica y territorio: factores de localización}

La globalización determina un nuevo contexto tanto para las empresas como para las ciudades, lo que exige nuevas fórmulas y estrategias que se adecuen a este entorno altamente dinámico caracterizado por una mayor incertidumbre y una creciente competitividad (Marcuse y van Kempen, 2000; Sassen, 2001). La globalización no únicamente estimula y cambia las condiciones para la competitividad empresarial, necesitada actualmente de un mejor acceso a la información, un capital humano altamente cualificado y nuevas formas de cooperación y colaboración, sino que plantea nuevos retos para aquellas ciudades capaces de ofrecer estas condiciones. La construcción de la acción colectiva a través de la participación e implicación de todos sus actores (ciudadanía, empresas e instituciones) en un territorio determinado permite afirmar que las ciudades, y no solo las empresas, también compiten entre sí (Camagni, 2005).

El desarrollo y la localización de actividades económicas en un entorno regional, particularmente las actividades creativas y de conocimiento, tienden a estar relacionados con aspectos imbricados en la historia local. Es decir, con una serie de elementos que han sido determinantes en la dinámica histórica de la ciudad o región. Se trata de un conjunto de aspectos que conforman la path dependency de una ciudad o región (Mahoney, 2000; Musterd et al. 2007; Bontje et al. 2011), es decir, el conjunto de elementos históricos que han tenido una influencia determinante en la caracterización de lo que hoy es una ciudad o una región metropolitana y que se resumen en:

- la propia dimensión económica, social y demográfica de la ciudad/región y de los cambios que ha experimentado; 
- los elementos institucionales existentes, no solamente aquellos de carácter político y formal, sino también aquellos de carácter informal que están enraizados en el propio carácter de la ciudad/región, desarrollo de los negocios y orientación de la ciudad hacia los mismos;

- el desarrollo urbanístico e histórico de la propia ciudad, así como de los elementos que lo han propiciado: mercado inmobiliario, patrimonio cultural, espacios públicos;

- los eventos que han sido determinantes en el desarrollo de la ciudad y la relación de dichos eventos con los aspectos señalados anteriormente.

En una perspectiva temporal, estos elementos han tenido una influencia decisiva en el desarrollo económico y social de ciudades y regiones, ya sea en su orientación comercial, manufacturera y financiera como cultural, artística, etc. El resultado de la vía seguida por cada región metropolitana es el actual grado de desarrollo de su actividad económica y de su sociedad. Es decir, el desarrollo de sus sectores industriales, la diversificación de los mismos y la interrelación o interdependencia surgida a lo largo del tiempo; en definitiva, la riqueza de su tejido industrial y de la propia sociedad.

Sin embargo, la importancia de la tradición y la historia no menoscaba el hecho de que las ventajas competitivas del territorio deben ser, hoy más que nunca, de carácter dinámico, ya que deben favorecer el flujo constante de innovaciones. De este modo, las tradicionales ventajas comparativas fundamentadas en la disponibilidad de recursos o la dotación de factores tienen cada vez un papel menor, mientras que las estrategias orientadas a crear nuevas ventajas específicas o a construir especificidades territoriales adquieren una importancia creciente (Camagni, 2005).

Las ciudades/regiones objeto de estudio del artículo son: Barcelona, Bilbao, Madrid y Valencia. Las cuatro ciudades poseen una importante área metropolitana que alberga tejido industrial con diverso grado de diversificación y que se extiende por su correspondiente comunidad autónoma. Cada una de las regiones ha tenido su path dependency específica, pero en todos los casos hay una coincidencia de objetivos: la consecución de la competitividad sobre la base de los nuevos parámetros de la economía actual. Ello permite el análisis de similitudes, diferencias, competitividad, complementariedades o sinergias entre las regiones, dado que, además, constituyen los cuatro vértices del cuadrante nordeste de España, una de las zonas que concentra el mayor crecimiento económico y demográfico del país. La economía creativa o del conocimiento tiene un impacto territorial evidente y se ha convertido no solo en una de las actividades más selectivas en cuanto a exigencias territoriales sino también en la que valoriza determinadas ciudades medias en España (Méndez et al. 2012).

Las regiones compiten en un conjunto variado de frentes (su ubicación, la variedad de recursos de que disponen, la calidad de vida y las infraestructuras, entre otros), cuyos factores clave para el éxito son el capital humano, la capacidad para la innovación, las infraestructuras de servicios, una financiación 
adecuada para las empresas, un sistema fiscal justo y eficiente y la cohesión de un tejido social (Vives y Torrens, 2004). Con el creciente impacto de la globalización de los sistemas productivos, la competitividad deja de asentarse en la producción de productos de bajo coste para orientarse hacia la calidad y la innovación.

El camino elegido por cada aglomeración urbana con el fin de ser competitiva en el ámbito internacional varía en función de muchos elementos, entre ellos, el papel desempeñado por el sector público en la mejora y la elaboración de varias estrategias para hacer frente a la competencia a través de la provisión de bienes públicos (infraestructuras de transporte y comunicación, la inversión en I + D, educación y centros de investigación competitivos), la planificación urbana y la prestación de los servicios públicos, junto con la provisión de garantías para que el mercado funcione de forma eficiente y competitiva.

Sin embargo, no son solo la estructura económica, la especialización, el modo de producción y la escala los factores importantes. La creatividad como tal también parece haber obtenido la condición de ser necesaria para alcanzar el éxito en la economía y en el desarrollo urbano (Musterd et al, 2007). La creatividad, pues, parece ser una condición crucial para el desarrollo en diversos ámbitos económicos como motor de innovación y de generación de conocimiento. Muchas de las regiones metropolitanas europeas han acogido con entusiasmo las industrias creativas y la atracción de la denominada «clase creativa» como centros neurálgicos de sus estrategias a largo plazo de desarrollo económico. Mientras que ciertas regiones tratan de perfilarse como «culturales» o "creativas», otras prefieren llamarse del «conocimiento». En cualquier caso, la contribución al crecimiento económico de estas regiones por parte de los sectores creativos y del conocimiento es la que finalmente determina la particular especialización de cada una.

Las regiones metropolitanas que constituyen los casos de estudio de este proyecto representan los vértices del cuadrante con mayor peso y dinamismo económico de España. La importancia económica de estas cuatro regiones urbanas supone uno de los factores clave en su elección como estudios de caso, pero no el único. Todas ellas han impulsado una espectacular transformación en las últimas décadas. Las nuevas estrategias de desarrollo urbanístico y económico han estado vinculadas, en los cuatro casos, a la nueva economía del conocimiento. Los sectores intensivos en conocimiento, pero también los creativos y las industrias culturales, ${ }^{1}$ han sido factores muy presentes en el desarrollo estratégico de estas ciudades regiones.

\section{El modelo productivo de la economía española: productividad, empleo y capital}

Durante las últimas tres décadas, la economía española ha experimentado los cambios más importantes de su historia reciente, marcados por su moderniza-

1. Véase la clasificación de estos sectores en la nota al pie de página número 8 . 
ción e internacionalización. Han sido también décadas de notable crecimiento económico, con tasas siempre superiores a las del entorno más próximo, el de los países de la zona euro. Sin embargo, dicho crecimiento no se ha conseguido sin importantes desequilibrios crónicos y en condiciones de difícil compatibilización del crecimiento económico con la creación de suficientes puestos de trabajo y crecimiento de la productividad.

Las características fundamentales de la evolución macroeconómica y sectorial de la economía española se analizan a continuación adoptando una perspectiva histórica de los últimos treinta años. Los datos utilizados proceden de tres bases de datos: EU KLEMS - Ivie, INE, Datacomex y Eurostat. ${ }^{2}$

\subsection{La productividad del trabajo}

El período comprendido entre 1995 y el comienzo de la recesión económica actual ha sido el período más prolongado de expansión económica de la economía española. Se identifican dos períodos claramente diferenciados en la evolución del crecimiento económico, de la productividad y del empleo: $1980-1995$ y $1996-2007$ (ver tabla 1 ).

El principal factor del crecimiento de la economía española hasta 1995 fue el crecimiento de la productividad del trabajo. A lo largo del período 19801995, el crecimiento de la productividad determinó que la creación de empleo fuera apenas perceptible, con un promedio de apenas ochenta mil empleos anuales. Por el contrario, durante el período 1995-2007, tanto el crecimiento económico como el del empleo fueron elevados, de manera que la economía española creó más del $34 \%$ del empleo de la zona euro; sin embargo, la tasa de crecimiento de la productividad fue solamente del $0,5 \%$ anual, muy inferior a la tasa de la zona euro, que fue del $1,3 \%$.

Las trayectorias en cuanto a productividad y crecimiento económico de los EE. UU. y la zona euro son divergentes a partir del año 1995: mientras

Tabla 1. Tasas de crecimiento acumulado de las variables macroeconómicas (en \%)

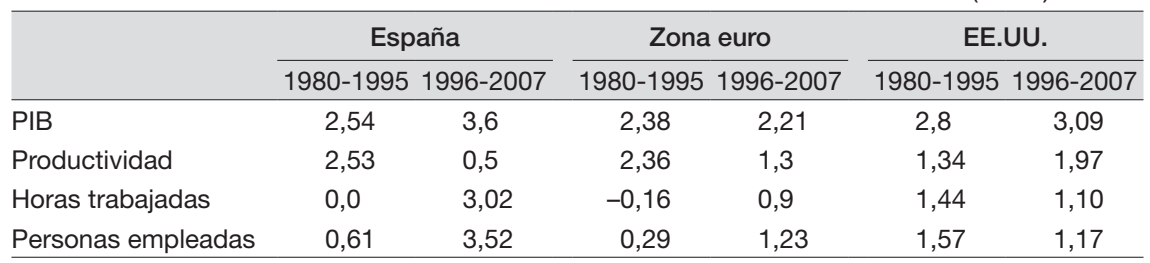

Fuente: EU KLEMS - Ivie y elaboración propia.

2. Algunos aspectos, como la periodificación o la exhaustividad de los datos autonómicos, vienen determinados por la disponibilidad de datos; así, por ejemplo, tomaremos como punto final de la serie del período de expansión el año 2007 o 2008, según la serie proceda de EU KLEMS - Ivie o del INE. 
que en EE. UU. se aceleró el crecimiento de la productividad y el crecimiento económico, en la zona euro ocurrió todo lo contrario. Además, la economía americana mostró más capacidad de creación de empleo a lo largo del periodo 1980-2007. El bajo crecimiento de la productividad en la zona euro se traduce en el debilitamiento de la competitividad, aunque de forma desigual, de la propia UE. Esto deja en entredicho los resultados conseguidos en el marco de la Agenda de Lisboa en el horizonte de $2010 .^{3}$ En el bajo crecimiento de la productividad y el retardo en la consecución de dichos objetivos radican algunas de las causas profundas de la actual crisis de los países del sur de Europa.

Un hecho diferencial que presenta la economía española con respecto a EE. UU y la zona euro es que, mientras que en EE. UU. y la zona euro mayores tasas de crecimiento de la productividad están asociadas a mayores tasas de crecimiento económico, en la economía española se produce lo contrario: mayores tasas de crecimiento de la productividad se asocian a menores tasas de crecimiento económico. Además, se hace patente la incapacidad de la economía española de conciliar el crecimiento importante de la productividad con el crecimiento del empleo.

En general, un menor crecimiento de la productividad del trabajo tiende a determinar un mayor crecimiento del coste laboral unitario, lo que se compensa con un menor crecimiento del margen de beneficios o un mayor crecimiento de los precios. En este último caso, el resultado es una menor competitividad. En consecuencia, conviene profundizar en el análisis del crecimiento de la productividad en la economía española en relación con la dotación de factores y su composición sectorial como elemento esencial del crecimiento económico y de la competitividad.

\subsection{La dotación de factores: capital y trabajo}

Ante el contraste entre el elevado crecimiento del PIB y el bajo crecimiento de la productividad de la economía española durante el período 1996-2007, un análisis pormenorizado de la aportación al crecimiento del PIB de la evolución del stock de capital y de la dotación de trabajo en España permite corroborar el débil posicionamiento de la economía española ante el reto del cambio de modelo productivo exigido por el contexto global.

Durante el periodo 1996-2007, tanto el crecimiento del empleo — se crean aproximadamente siete millones de empleos - como el crecimiento de la inversión - 5,2\% anual en términos reales $-{ }^{4}$ han sido muy elevados. El crecimiento de la inversión durante los años 2002-2008, en promedio, fue mayor que el del entorno internacional más próximo y superó en 7 puntos porcentuales la inversión correspondiente a la zona euro (ver gráfico 1).

Así pues, a lo largo del período de expansión de la economía española (1996-2008) se produjo un elevado aumento de la inversión, con un cre-

3. <http://www.europarl.europa.eu/summits/lis1_es.htm>

4. Superior al $4 \%$ experimentado durante el período comprendido entre 1980 y 1995. 


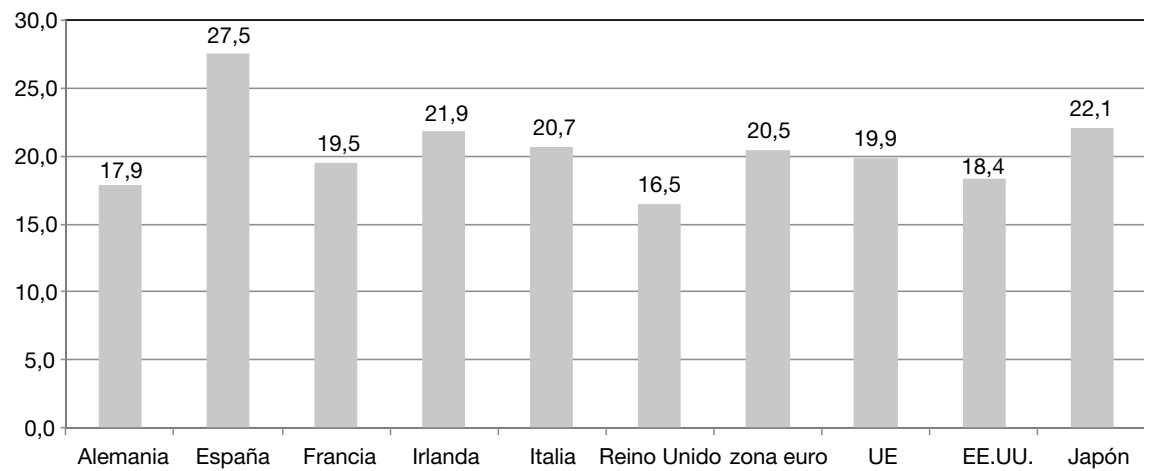

Gráfico 1. Participación promedio de la inversión sobre el PIB 2002-2010 (en \%).

Fuente: Eurostat, varios años.

cimiento medio superior al crecimiento del empleo, por lo que se produjo también un incremento de la relación capital/trabajo. Tanto la inversión como el empleo crecieron a un ritmo superior al crecimiento del PIB; sin embargo, el crecimiento de la productividad fue muy bajo, lo que supone uno de los graves inconvenientes de la economía española, si no el mayor. Existen, pues, deficiencias importantes en la utilización eficiente de los recursos productivos en buena parte de la economía española.

Un análisis alternativo mediante la contabilidad del crecimiento económico (Mas y Robledo, 2010; Pérez y Robledo, 2010; Banco de España, 2011; Myro, 2011) consiste en la descomposición del mismo de acuerdo con las variables que emanan de la función de producción: la aportación del factor capital, la aportación del factor trabajo y la productividad total de los factores. ${ }^{5} \mathrm{El}$ resultado de este método de contabilización del crecimiento muestra una realidad todavía más negativa con respecto al papel de la productividad en este aspecto: el crecimiento de la productividad total de los factores en la economía española ha sido prácticamente nula durante el período considerado, incluso negativa, según cuál sea la contabilización de los factores productivos. En cambio, la participación de los recursos en el crecimiento económico ha sido elevada y explica, de acuerdo con dicha metodología, la mayor parte del crecimiento económico de la economía española durante dicho período.

El análisis detallado de la participación de los factores productivos en el crecimiento arroja luz sobre el problema del crecimiento y la productividad:

5. Dada la función de producción como la combinación de capital $(\mathrm{K})$ y trabajo $(\mathrm{L})$, se considera que el crecimiento derivado de la misma será el resultado de la suma ponderada de la inversión más el montante de trabajo más la productividad total de los factores, entendida esta como el plus resultante de la combinación de los factores en el proceso productivo. 
a) Composición del capital: el desglose de la composición de la inversión durante el período muestra el mayor crecimiento de algunos de los componentes generales de la inversión: vivienda, otras construcciones, equipo de transporte y maquinaria, material de equipo y otros productos (ver gráfico 2). Se observa claramente la correlación existente entre la inversión en vivienda y la evolución del ciclo de la inversión y la del ciclo económico general; en el momento de auge económico, año 2006, la inversión en vivienda superó el $37 \%$ de la inversión total de la economía española, mientras que disminuyó drásticamente hasta el $25 \%$ del total en 2010.

La evolución de los demás componentes de la inversión en relación con el PIB ha sido más estable, particularmente la de aquellos que podemos considerar inversión productiva: equipo de transporte y maquinaria, material de equipo y otros productos. La crisis económica ha provocado una importante reducción de la inversión total, de casi el $10 \%$ anual acumulativo entre 2007 y 2010 , aunque con caídas superiores en vivienda, $15 \%$ anual, y equipo de transporte, $13 \%$ anual.

b) Composición del empleo. El empleo ha constituido la segunda fuente de crecimiento de la economía española. La tasa de crecimiento anual del empleo durante el período 1996-2007 fue similar a la tasa de crecimiento del PIB. Además, se ha producido una importante mejora de la calidad del capital humano, acreditada por un incremento de 2,8 millones de personas del número de ocupados universitarios, un aumento todavía mayor del número de ocupados con estudios medios, y una reducción de 1,7 millones de personas del número de ocupados sin estudios o con estudios primarios.

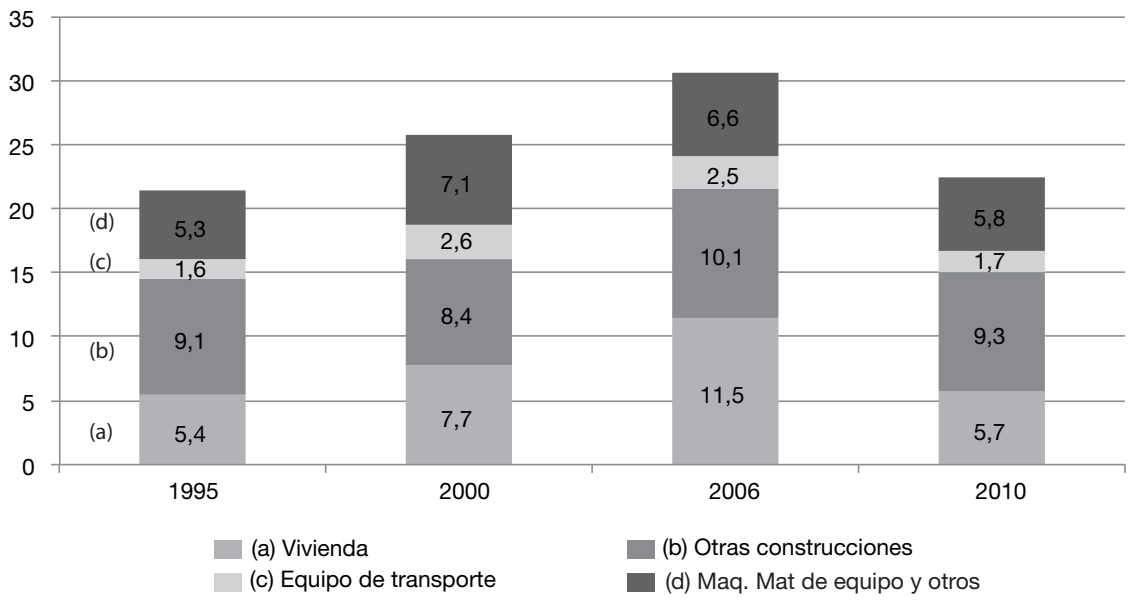

Gráfico 2. Inversión nominal bruta por componentes (en \% del PIB).

Fuente: Fundación BBVA-Ivie. 
La existencia de sobrecualificación, entendida como el porcentaje de personas con educación terciaria o superior que ocupan puestos de trabajo de cualificación media o baja (Eurostat, 2011), pone de manifiesto el desajuste existente entre la formación de la mano de obra y el sistema productivo, incapaz de generar puestos de trabajo para absorberla; es decir, una ineficiente utilización del capital humano que puede contribuir a la explicación del bajo crecimiento de la productividad de la economía española. La elevada tasa de sobrecualificación de la economía española significa que la eficiencia en el uso del capital humano es de las más bajas de la UE (ver gráfico 3).

La sobrecualificación de la mano de obra de la economía española es un problema endémico y no exento de controversia. Tres factores explican la deficiente adecuación del capital humano al sistema productivo español (TorrentSellens et al., 2009; Serrano, 2010).

- Las posibles deficiencias de formación que apuntan estudios comparativos como PISA (OCDE, 2009), lo que en realidad relativiza la magnitud de dicha sobrecualificación en la medida en que puede mostrar ciertas deficiencias de algunos niveles formativos.

- Una utilización poco eficiente del capital humano por las empresas debido a la existencia de desajustes entre la formación y su adecuación al puesto de trabajo concreto, a las dificultades de adaptación de algunos trabajadores inmigrantes y, sobre todo, a la temporalidad de los contratos (Fundación BBVA, 2010).

- Un retraso en la materialización del potencial del capital humano de los trabajadores por falta de acumulación de experiencia, es decir, un retardo de aprendizaje.

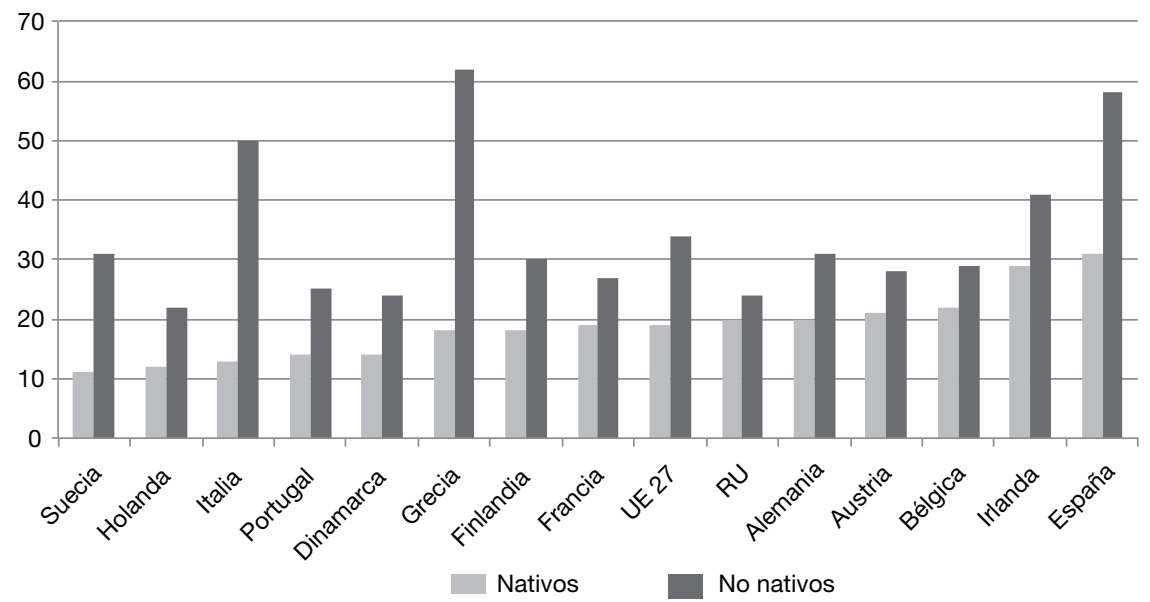

Gráfico 3. Sobrecualificación de la población ocupada de 25 a 54 años (en \%). 2008. Fuente: Eurostat, 2011. 
A ello se debe añadir la considerable entrada de inmigración desde finales de los años noventa hasta el inicio de la crisis, motivada esencialmente por la búsqueda de oportunidades de trabajo, la mayoría en sectores de poco valor añadido como el sector de la construcción o los servicios al hogar, independientemente de la aportación en términos de cualificación de los inmigrantes (Hernández Pedreño y Tovar Arce, 2005).

En definitiva, todo ello determina que la economía española no aproveche plenamente su dotación de factores productivos, es decir, que la combinación de capital y trabajo dentro de la empresa no obtenga los resultados que por la calidad de la inversión y, sobre todo, por la cualificación del capital humano, debieran obtenerse.

\subsection{Análisis sectorial y crecimiento económico}

Tal y como ya se ha mencionado anteriormente, el período 1996-2007 ha sido el de mayor crecimiento continuado de la economía española durante las últimas décadas. Sin embargo, el crecimiento de los sectores manufactureros no ha evolucionado de manera acorde con el del conjunto de la economía. El crecimiento acumulado de las manufacturas españolas ha sido del 1,7 \% anual desde 1995 hasta el inicio de la crisis económica, pero con tendencia hacia la desaceleración: entre 2000 y 2007 el crecimiento del sector manufacturero fue de apenas el 0,5\% anual acumulado, muy inferior al crecimiento del resto de sectores (Contabilidad Nacional de España, INE, varios años). Las manufacturas han tenido un protagonismo destacado durante la crisis económica, con una caída superior al $9 \%$ entre 2008 y 2011. Por el contrario, los servicios en su conjunto experimentaron un crecimiento del 3,6 \% superior al conjunto de la economía, durante los primeros ocho años del siglo XXI, y una tenue caída del $-0,3 \%$ anual entre 2008 y 2011 . Asimismo, los sectores que presentan para el periodo 1996-2007 una tasa de crecimiento del valor añadido por encima de la media (ver tabla 2) son fundamentalmente sectores de servicios (9 de 13), la mayoría de ellos intensivos en conocimiento.

Esto acentúa el cambio estructural de la economía española hacia un mayor peso de los servicios, especialmente de los denominados servicios cuaternarios y quinarios. ${ }^{6}$ Esta atrofia de las actividades manufactureras frente al resto de actividades referidas puede explicarse en gran medida por dos causas: la apreciación del tipo de cambio real de la economía española frente al exterior, zona euro y resto del mundo, y las políticas de liberalización del suelo y de fomento de las actividades de la construcción e inmobiliarias; elementos que, junto a la facilidad del crédito, constituyeron los fundamentos de la burbuja generada en la economía española (Puig, 2011) (Pareja-Eastaway y Sánchez-Martínez,

6. En un sentido amplio, los sectores cuaternarios están comprendidos por las TIC, la consultoría y servicios a empresas, finanzas y seguros, las actividades profesionales, científicas y técnicas, la I + D y las telecomunicaciones. Los servicios quinarios comprenden las actividades culturales, las artes y representaciones escénicas, actividades relacionadas con el patrimonio, la educación y las actividades sanitarias. 
Tabla 2. Sectores de mayor dinamismo en cuanto a FBKF y VA sectorial (en \%). Tasa de crecimiento anual medio 1996-2007

\begin{tabular}{lrc}
\hline & FBKF & VA \\
\hline Actividades informáticas & 16,60 & 9,48 \\
Intermediación financiera & 11,34 & 6,58 \\
Correos y telecomunicaciones & 7,26 & 6,13 \\
Investigación y desarrollo & & 5,90 \\
Construcción aeronáutica y espacial & 10,91 & 5,84 \\
Construcción & 13,39 & 5,17 \\
Otras actividades empresariales & 15,61 & 5,15 \\
Fabricación de maquinaria y material eléctrico & 11,61 & 4,66 \\
Impresión y reproducción de soportes gravados & 9,25 & 4,12 \\
Actividades inmobiliarias & 8,51 & 4,04 \\
Sanidad y servicios sociales & 8,23 & 3,82 \\
Edición & 8,61 & 3,79 \\
Actividades de cine, vídeo, radio y televisión & 5,64 & 3,67 \\
TOTAL SECTORIAL & 7,87 & 3,59 \\
\hline
\end{tabular}

Fuente: EU KELMS - Ivie y elaboración propia. FBKF (Formación Bruta de Capital Fijo); VA (valor añadido)

2011). En conjunto, ambos elementos determinaron una asignación de recursos adversa a los sectores productivos manufactureros, más proclives a la mejora tecnológica y más orientada a la exportación. Estos sectores son los que, por su naturaleza, tienden a experimentar mayores incrementos de productividad.

\section{La dimensión territorial y el modelo productivo en España: el caso de Barcelona, Bilbao, Madrid y Valencia}

La elección de las comunidades autónomas (CC. AA.) como objeto de estudio viene condicionada por la disponibilidad de datos sectoriales al mínimo nivel requerido de desagregación. Así, si bien el objetivo es el análisis de las ciudadesregiones de Barcelona, Bilbao, Madrid y Valencia, la restricción impuesta por los datos disponibles remite al marco de las CC. AA.: Cataluña, País Vasco, Madrid y Comunidad Valenciana. ${ }^{7}$ Las cuatro CC. AA. mencionadas abarcan más del $52 \%$ del PIB español (Contabilidad Nacional, INE, varios años) y, particularmente, las cuatro provincias que constituyen los principales centros de aglomeración económica regional abarcan cerca del 40 \% del PIB de España, más del $42 \%$ de la industria manufacturera española y más del $41 \%$ de los servicios, tomando como referencia los datos provinciales sobre el total nacional. Las CC. AA. estudiadas han sido grandes receptoras de inmigración extranjera, especialmente Cataluña, Madrid y la Comunidad Valenciana.

7. El nivel de desagregación de los datos ofrecidos por los centros estadísticos se reduce conforme lo hace el ámbito geográfico de los mismos, de manera que los datos disponibles en el ámbito provincial, el más próximo al de ciudad-región, son de escasa desagregación, lo que dificulta las posibilidades de estudio a dicho nivel. 
Este peso de las ciudades-regiones sobre el conjunto autonómico permite una buena aproximación al análisis de las aglomeraciones metropolitanas de las respectivas ciudades-regiones mediante el uso de los datos autonómicos. Este recurso no precisa justificación en el caso de Madrid, en el que ambos ámbitos, ciudad-región y autonomía, coinciden; sin embargo, puede justificarse en los casos de Vizcaya y Valencia, cuyo PIB supera el $52 \%$ y el $53 \%$ del PIB autonómico, respectivamente, y sobre todo en el caso de Barcelona, cuyo PIB está en torno a los $2 / 3$ del PIB autonómico. Por otra parte, puesto que los sectores analizados son, por sus características, propiamente urbanos, la mayor concentración de sus actividades se da en los entornos urbanos estudiados.

\subsection{Especialización productiva y competitividad de las cuatro CC. AA.}

Las cuatro CC. AA. representan a los territorios con más tradición de desarrollo de la industria manufacturera y, por lo tanto, han constituido los principales centros de atracción de población inmigrante procedente tanto del interior como del exterior. La crisis económica de los años setenta constituye un punto de inflexión en la evolución de las sociedades industriales, que experimentaron la pérdida de muchas de sus ventajas comparativas e iniciaron la progresiva terciarización de las economías (Etxezarreta, 1991). El impacto de la crisis de los setenta fue desigual en cada una de las CC. AA. estudiadas. En Vizcaya fue elevado y motivó una larga reconversión industrial partiendo desde la industria siderúrgica y metalúrgica. También se dejó notar en Barcelona, en donde el sector textil era preponderante antes de 1970 y cuya reconversión supuso una importante ralentización económica y la pérdida de la supremacía económica de Barcelona (provincia) en la economía española (Sudrià, 2002) V Valencia, con menor peso relativo de la industria manufacturera y menor grado de internacionalización, y Madrid, con una economía más orientada hacia los servicios, subsistieron relativamente mejor a los efectos de la crisis.

El análisis por CC. AA. confirma la dimensión territorial del desarrollo general de la economía española, tanto en cuanto al crecimiento económico como en cuanto a la predisposición futura de crecimiento de cada una de las regiones metropolitanas, si bien pueden distinguirse las peculiaridades propias de cada una de las CC. AA., que vienen determinadas en parte por su path dependency (figura 1).

Las regiones con menor peso de las actividades manufactureras, Madrid y Valencia, han sido las que han experimentado un mayor crecimiento económico entre 2000 y 2008, mientras que Catalunya y el País Vasco han visto lastrado su crecimiento por el mayor peso de las manufacturas (ver anexo 2). Sin embargo, en estas dos últimas CC. AA., el conjunto de las manufacturas ha tenido mejor comportamiento desde 2009, con una recuperación más rápida que en la Comunidad de Madrid y, sobre todo, que en la Comunidad Valenciana.

La especialización productiva de las cuatro CC. AA. estudiadas durante el período 2008-2011 (ver anexo 1) refleja una elevada especialización de Cataluña y el País Vasco en la mayoría de las actividades manufactureras, algunas de 


\begin{abstract}
Madrid presenta un menor número de empresas y un mayor tamaño promedio en número de asalariados que el resto de ciudades/regiones (mayor número de grandes empresas è mayor número de empresas tractoras è núcleos de posibles clústeres). Esto se explica por el efecto capitalidad y centralidad del mercado español $y$, en algunos casos, latino (edición, medios...). Política de arriba abajo de estímulo (de clústeres) en la Comunidad de Madrid.

Bilbao denota una estructura productiva similar a Cataluña, si bien el giro es más reciente y precipitado que en Barcelona. Bilbao tuvo una tradición de grandes empresas siderúrgicas y metalúrgicas, lo que determinó buenas condiciones de clusterización. Este aspecto ha perdurado en actividades de conocimiento, importantes en Bilbao; Bilbao no tiene gran experiencia en actividades creativas. Su grado de internacionalización es mucho menor que el de Barcelona o Madrid, por lo que todo se realiza a partir de lo existente.
\end{abstract}

Figura 1. Breve síntesis del tejido productivo y estrategia productiva. Madrid, Barcelona, Bilbao, Valencia.

ellas intensivas en conocimiento, como el caso de los «Productos informáticos, electrónicos y ópticos, equipo eléctrico y otros productos», y el de "Coquerías y refino de petróleo, industria química y fabricación de productos farmacéuticos», importante en Cataluña, entre otras razones, por la potente industria farmacéutica. La especialización manufacturera es menor en la Comunidad Valenciana, con incidencia en actividades más intensivas en trabajo, y nula en la Comunidad de Madrid. En cambio, Madrid tiene una fuerte especialización en una parte importante de actividades de servicios, particularmente en los sectores cuaternarios y quinarios, es decir, en muchos de los que están estrechamente relacionados con la actividad productiva empresarial. Claramente, el peso de estos sectores en la Comunidad de Madrid supera las necesidades de la propia demanda regional, lo que significa que se trata de actividades orientadas en gran parte a la exportación, tanto al mercado nacional como al internacional (González-López, 2009).

El bajo crecimiento de la productividad aparente para el conjunto de la economía española (tabla 1) también se ha producido en la economía de las CC. AA. objeto de estudio: se ha reproducido el mismo patrón de crecimiento económico basado en un fuerte aumento del empleo y de la inversión, pero en un bajo crecimiento de la productividad. En efecto, el crecimiento anual de la productividad entre 2000 y 2007 fue prácticamente nulo en Cataluña y en Madrid, ligeramente negativo en la Comunidad Valenciana $(-0,22)$ y apenas 
creció el 0,36 \% en el País Vasco, de acuerdo con los datos de la Contabilidad Nacional y de la Contabilidad Regional de España elaborados por el INE. No obstante, el análisis sectorial, realizado a partir esos mismos datos, revela un elevado crecimiento de la productividad en el sector de «Intermediarios financieros», con tasas de crecimiento anual cercanas al $8 \%$ en las cuatro comunidades autónomas y tasas moderadas en el conjunto de las manufacturas, entre el $0,6 \%$ en la Comunidad Valenciana y el 1,3\% en Madrid.

Por otro lado y de acuerdo con las mismas fuentes, también se observa un elevado crecimiento del excedente bruto de explotación entre 2000 y 2007, del $7 \%$ medio anual, aunque en algún sector, como el de «Intermediarios financieros", llegó a tasas medias de crecimiento anual de dos dígitos; el crecimiento salarial medio durante el período fue del 3,6 \%. Excepto en el caso del sector financiero, parece evidente que las remuneraciones de los factores crecieron a un ritmo muy superior a la productividad, sin que en todos los casos se pudieran evidenciar mejoras de la calidad.

\subsection{Los sectores creativos y del conocimiento en las cuatro CC. $A$ A.}

Siguiendo la argumentación desarrollada en el epígrafe 2 de este artículo, la competitividad de las ciudades y territorios se basa hoy en parámetros distintos a las ventajas en costes de los factores o precios. El desafío al que se enfrentan hoy las cuatro regiones metropolitanas objeto de estudio ante la necesidad de estimular su desarrollo económico y crear empleo y crecimiento es el de generar, atraer y retener actividades creativas y de conocimiento. Aumentar la creación territorial de valor añadido a través del asentamiento de empresas, trabajadores y profesionales vinculados a estos sectores es probablemente la única vía de reconducir la economía española hacia un nuevo modelo productivo.

En este artículo, los sectores objeto de análisis son los sectores creativos y de conocimiento seleccionados sobre la base de la CNAE 2009 (UNCTAD 2010). ${ }^{8}$ En un sentido amplio, podemos considerar que en cualquier actividad económica hay aspectos de creatividad y cualquier actividad económica requiere un mínimo conocimiento. En consecuencia, el contenido de ambos

8. Siguiendo el criterio de UNCTAD, se clasifican los sectores analizados en: Creativos: 58. Edición (58.1 Edición de libros, periódicos y otras actividades editoriales; 58.2 Edición de programas informativos), 59. Actividades cinematográficas, de vídeo y de programas de televisión, grabación de sonido y edición musical. (Excepto 59.17 y 59.18: actividades de distribución) 60. Actividades de programación y emisión de radio y televisión (63.12. Portales web) 71.11. Servicios técnicos de arquitectura 73.1. Publicidad; 74.1. Actividades de diseño especializado 74.2. Actividades de fotografía. 90. Actividades de creación artística y espectáculos. 61.1. Actividades de Biblioteca, archivos, museos y otras actividades culturales. Conocimiento: 61. Telecomunicaciones; 62. Programación y consultoría informática; 63. Servicios de información (Excepto 63.12); 64, 65, 66. Finanzas y seguros y servicios auxiliares; 69.1. Actividades jurídicas; 70. Actividades de sedes centrales, actividades de consultoría y de gestión empresarial; 71.12. Servicios técnicos de ingeniería; 71.2. Ensayos y análisis técnicos; 72. Investigación y desarrollo. 85.4. Educación post-secundaria. 
aspectos es una cuestión de grado. La Clasificación Nacional de Actividades Económicas (CNAE), siguiendo las clasificaciones NACE anteriores, ha ido perfilando las diferencias entre actividades recogiendo cada vez más el criterio de distinción de intensidad en conocimiento y creatividad.

Dos elementos merecen destacarse acerca de la evolución del número de empresas en las cuatro CC. AA. objeto de estudio (ver gráfico 4): por un lado, la relativa supremacía de Madrid en cuanto a número de empresas tanto creativas como del conocimiento, con una clara superioridad respecto a los otros tres territorios. Por otro lado, mientras el número de empresas creativas sufre un relativo estancamiento a lo largo del periodo 2008-2011, el número de empresas del conocimiento presenta signos evidentes de crecimiento en todas las CC. AA., particularmente en Madrid.

En efecto, un análisis alternativo basado en la creación de empleo en las cuatro CC. AA. por parte de sectores creativos y del conocimiento en el periodo más duro de la crisis económica que atraviesa España (ver gráfico 5) pone

Empresas de sectores creativos sobre el total

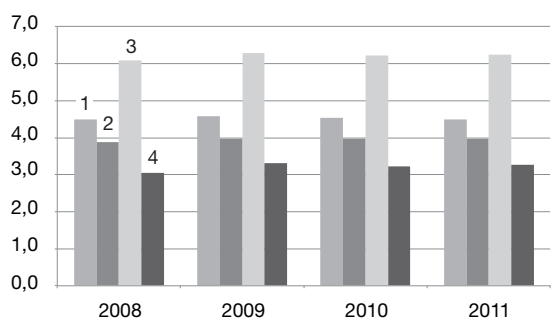

Empresas de sectores del conocimiento

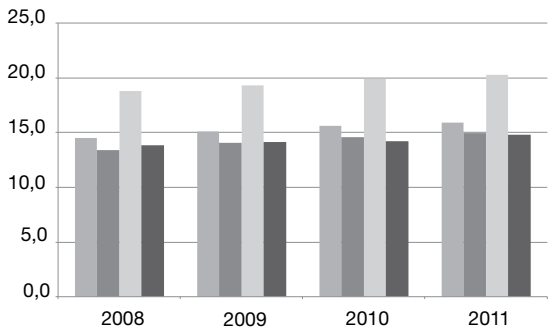

Gráfico 4. Número de empresas en sectores creativos y del conocimiento. (1) Cataluña; (2) Comunidad Valenciana; (3) Comunidad de Madrid; (4) País Vasco (2008-2011).

Fuente: INE, Directorio Central de Empresas.

Empleo en sectores creativos sobre el total

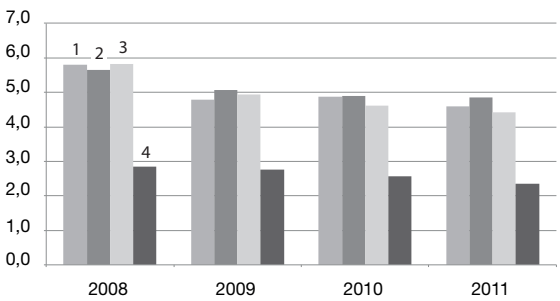

Empleo en sectores de conocimiento sobre el total

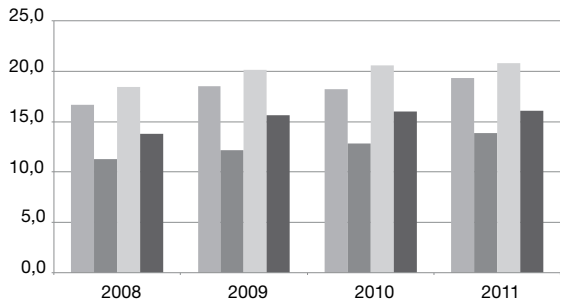

Gráfico 5. Empleo en sectores creativos y del conocimiento. (1) Cataluña; (2) Comunidad Valenciana; (3) Comunidad de Madrid; (4) País Vasco (2008-2011).

Fuente: INE, Directorio Central de Empresas. 
claramente de manifiesto un hecho común a los cuatro territorios: mientras que el empleo generado por las industrias creativas decrece ostensiblemente año tras año en los cuatro territorios, la contribución a la generación de empleo de las actividades del conocimiento es de signo positivo y creciente durante este periodo.

En definitiva, tanto Madrid como Cataluña presentan una clara especialización en sectores creativos e intensivos en conocimiento; destaca la especialización de Madrid en sectores del conocimiento, mientras que la Comunidad Valenciana tiene escasa especialización en sectores intensivos en conocimiento y el País Vasco tiene limitada especialización en sectores creativos.

De acuerdo con las perspectivas del FMI y de la mayoría de instituciones y centros de prospectiva, la demanda interna de la economía española experimentará una prolongada atonía, por lo que la actual crisis económica deberá reforzar la internacionalización comercial de la economía española, particularmente por el lado de las exportaciones. Hay que recordar que el recurso al crecimiento de las exportaciones ha sido tradicional en las recuperaciones de la economía española después de las sucesivas crisis padecidas; se trata de buscar en el exterior la demanda de mercado que se ha perdido en el interior.

Por otra parte, desde el punto de vista de la orientación del desarrollo productivo, los sectores creativos e intensivos en conocimiento precisan de un impulso hacia su internacionalización, y a su vez son claves desde el punto de vista estratégico de la internacionalización de las regiones metropolitanas estudiadas (Pareja-Eastaway et al., 2008). Los territorios estudiados son los que presentan mayor potencial exportador (ver tabla 3), ya que suponen más del $58 \%$ de las ventas al exterior, si bien su dinamismo es desigual y destaca el bajo crecimiento de las exportaciones valencianas.

Las cuatro CC. AA. concentran más del $71 \%$ en los sectores creativos e intensivos en conocimiento, si bien en torno al $55 \%$ de dichas exportaciones proceden de Cataluña y Madrid. Destacan por el mayor crecimiento de las exportaciones los sectores de "Confección de prendas de vestir», en Cataluña, «Productos farmacéuticos», en Cataluña y Madrid, «Construcción aeronáutica

Tabla 3. Exportaciones totales y de sectores creativos e intensivos en conocimiento. Crecimiento y participación porcentual

\begin{tabular}{|c|c|c|c|c|}
\hline & $\begin{array}{l}\text { Participación de } \\
\text { las exportaciones } \\
\text { totales }\end{array}$ & $\begin{array}{l}\text { Crecimiento medio } \\
\text { de las exportaciones } \\
\text { totales 2000-2011 }\end{array}$ & $\begin{array}{l}\text { Exportaciones } \\
\text { de sectores creativos y } \\
\text { de conocimiento sobre } \\
\text { el total de exportaciones } \\
\text { de cada C. A. }\end{array}$ & $\begin{array}{l}\text { Exportaciones de } \\
\text { sectores creativos y de } \\
\text { conocimiento sobre el } \\
\text { total de exportaciones } \\
\text { españolas }\end{array}$ \\
\hline España & 100 & 5,1 & 17,7 & 17,7 \\
\hline Cataluña & 26,8 & 4,7 & 20,9 & 5,6 \\
\hline Madrid & 11,1 & 5,3 & 37,9 & 4,2 \\
\hline C.Valenciana & 11,0 & 2,5 & 14,9 & 1,6 \\
\hline País Vasco & 9,5 & 5,6 & 7,5 & 0,7 \\
\hline
\end{tabular}

Fuente: Datacomex y elaboración propia. 
y espacial», en Madrid, "Otras actividades profesionales científicas y técnicas», en Cataluña, y "Actividades de creación, artísticas y espectáculos».

Así pues, estas regiones, especialmente Madrid y Barcelona/Cataluña, tienen una especial predisposición para la internacionalización productiva y comercial, especialmente en actividades creativas e intensivas en conocimiento, lo que las habilita para constituirse en locomotoras del crecimiento de la economía española.

\section{Conclusiones}

La necesidad de transformar el modelo productivo en España se hace manifiesta a partir de las dificultades evidentes que se presentan desde el año 2008 ante la necesidad de generar crecimiento económico, reducir las tasas de desempleo y reorientar la especialización productiva hacia sectores con alto valor añadido.

El periodo de expansión previo a la crisis económica que vivió la economía española desde 1996 se fundamenta en unas bases de difícil justificación, particularmente al compararlas con el conjunto de la zona euro o los EE. UU. A saber, un crecimiento del PIB y del empleo sostenido a pesar de la grave caída de la productividad del trabajo. Sectorialmente, este fenómeno se explica por el crecimiento sostenido de sectores como el de la vivienda, basado en una productividad baja y una reducida aportación de valor añadido.

Además, otra consecuencia preocupante del análisis del crecimiento sectorial y del crecimiento de la productividad de la economía española es la de que, pese a que se ha producido un notable crecimiento de sectores intensivos en conocimiento, ello no se ha traducido en un correspondiente incremento de la productividad. Se confirma la existencia de un problema general de uso ineficaz de los factores productivos. En efecto, se da la circunstancia de que se ha producido un importante incremento de la inversión productiva, así como una mejora del capital humano, que no se han transformado en una mejora de la productividad.

A pesar de que los sectores o actividades de mayor crecimiento económico desde 1996 han sido aquellos más intensivos en conocimiento y, por lo tanto, con mayor potencial de crecimiento de la productividad, los resultados no refrendan lo que lógicamente debería deducirse de la coincidencia de los tres aspectos reseñados, a saber, mejora de la inversión, del empleo y de la calidad del capital humano.

La dimensión local de la competencia global exige al territorio una apuesta decidida por la atracción de empresas basadas en la creatividad, el conocimiento y la innovación, así como profesionales cualificados que evidencian nuevas fuentes de ventajas competitivas, más allá de la reducción de costes y precios en aras de mayores tasas de exportación. La presencia y el reconocimiento de la trayectoria económica de cada territorio (path dependency) le dota de unicidad y asienta el crecimiento en unas bases que son determinadas por el dinamismo de cada región. Ello sin menoscabar, por supuesto, la capacidad de las estrategias de política urbana de arriba abajo, que apoyan a sectores considerados necesarios y completamente emergentes en el contexto local. 
Las uatro CC. AA. consideradas traducen a escala territorial los grandes problemas del modelo de desarrollo económico de la economía española partiendo de diferentes especializaciones productivas y distintos pesos relativos en el conjunto de la economía española. Sin embargo, en cuanto a la capacidad de generación de empresas y empleo en sectores creativos y del conocimiento después de la crisis, mostrando así la capacidad de reacción de cada territorio, denotan simultáneamente puntos en común y notables divergencias: mientras en actividades creativas las cuatro regiones muestran una tendencia al estancamiento (número de empresas) o reducción (empleo), las actividades del conocimiento evidencian signos positivos de crecimiento en ambas categorías. El posicionamiento relativo y la reacción ante la crisis de cada uno de estos territorios valida en mayor o menor medida la adopción de un modelo que estimula y promueve el asentamiento de las actividades asociadas con el conocimiento. No cabe duda de que Madrid lidera este proceso seguido por Cataluña. Más allá de la exploración cuantitativa, los factores explicativos recalan en la adopción de una determinada estrategia de ciudad que permite traducir en creación de empleo y, por lo tanto, en mejores oportunidades para superar la crisis económica, la localización de empresas y profesionales que contribuyen a crear un alto valor añadido en el territorio.

La mejoría de la calidad del factor trabajo, medida en función del número de titulados universitarios, durante el período de expansión de la economía española ha sido puesta de manifiesto; la capacidad de las regiones metropolitanas estudiadas de generar actividades creativas e intensivas en conocimiento también es patente. Sin embargo, uno de los retos pendientes es traducir la calidad existente de la mano de obra en calidad del crecimiento económico. La consecución de dicho objetivo debería conllevar avances significativos en la innovación a través de una mayor implicación de algunas actividades creativas e intensivas en conocimiento en la actividad productiva. En este contexto deberían avanzar las políticas públicas a escala nacional de apoyo al crecimiento económico, sin olvidar su complementariedad con las iniciativas de arriba abajo a escala local o regional.

\section{Referencias bibliográficas}

BANCO DE EsPAÑA (2011). Sintesis de indicadores. <http://www.bde.es/webbde/es/ estadis/infoest/sindi.html>

Bontje, M.; Musterd, S. y Pelzer, P. (2011). Inventive City-Regions. Path Dependence and Creative Knowledge Strategies. Surrey: Ashgate. Urban and Regional Planning and Development Series.

DataComex (varios años). Ministerio de Economía y Competitividad. <http:// datacomex.comercio.es/principal_comex_es.aspx>

CAMagni, R. (2005). Economía urbana. Barcelona: Antoni Bosch.

Cooke, P. y Simmie, J. (2005). "Knowledge, Innovation and the Competitiveness of Cities». En: Buck, N.; Gordon, I.; Harding, A. y Turok, I. (2005). Changing Cities. Rethinking Urban Competitiveness, Cohesion and Governance. Hampshire: Palgrave McMillan. 
EtXeZARreta, M. (1991). La reestructuración del capitalismo en España, 1970-1990. Barcelona: Icaria. Economía Crítica.

EU KLEMS-IVIE (varios años). <http://www.euklems.net>

Eurostat (2011). «Migrants in Europe. A statistical portrait of the first and second generation». <http://epp.eurostat.ec.europa.eu/cache/ITY_OFFPUB/KS-31-10539/EN/KS-31-10-539-EN.PDF>

FELDman, M. (2000). «Location and Innovation: The New Economic Geography of Innovation, Spillovers, and Agglomeration». En: Clark, G.; Gertler, M. y Feldman, M. (eds.). The Oxford Handbook of Economic Geography. Oxford: Oxford University Press.

FUNDACIÓN BBVA (2010). «Fuentes del crecimiento de la productividad en España». Cuadernos Fundación BBVA, 7. <http://www.fbbva.es>.

GONZÁlEZ-LÓPEZ, M. (2009). "Regional differences in the growth patterns of knowledge-intensive business services: an approach based on the Spanish case». European Urban and Regional Studies, 16. 101-6.

INE (varios años). Contabilidad nacional de España. <http://www.ine.es/jaxi/menu. do?type $=$ pcaxis $\&$ path $=\% 2 \mathrm{Ft} 35 \% 2 \mathrm{Fp} 008 \&$ file $=$ inebase $\& \mathrm{~L}=0>$

INE (varios años): Contabilidad regional de España. <http://www.ine.es/jaxi/menu.do? type $=$ pcaxis \&path $=\% 2 \mathrm{Ft} 35 \% 2 \mathrm{Fp} 010 \&$ file $=$ inebase $\& \mathrm{~L}=0>$

INE (varios años): Directorio central de empresas. <http://www.ine.es/jaxi/menu.do?ty pe $=$ pcaxis $\&$ path $=\% 2 \mathrm{Ft} 37 \% 2 \mathrm{Fp} 201 \&$ file $=$ inebase $\& \mathrm{~L}=0>$

JaCOBS, J. (1984). Cities and the Wealth of Nations. Nueva York: Random House.

KRUGMAN, P. (1991). "Increasing returns and economic geography». Journal of Political Economy, 99, 483-99.

Hernández Pedreño, M. y Tovar Arce, M. (2005). «El capital humano de los inmigrantes». En: Pedreño Cánovas, A. y Hernández Pedreño, M. (coords.). La condición del inmigrante. Murcia: Universidad de Murcia.

LEVER, W. (2002). «The knowledge base and the competitive city». En: Begg, I. (ed.). Urban competitiveness. Policies for dynamic cities. Bristol: The Policy Press.

Mahoney, J. (2000). "Path dependence in historical sociology». Theory and Society 29, 507-48.

Mas, M. y Robledo, J. C. (2010). Productividad. Una perspectiva internacional y sectorial. Bilbao: Fundación BBVA.

Marcuse, P. y Van Kempen, R. (2000). Globalising Cities. Oxford: Blackwell Publishers.

MÉndeZ, R.; Michelini, J. J. ; PRADA, J. Y TÉBAR, J. (2012). «Economía creativa y desarrollo urbano en España: una aproximación a sus lógicas espaciales». Eure, 38 (113), 5-32.

Musterd, S.; Bontje, M.; Chapain, C.; Kovacs, Z. y Murie, A. (2007). «Accommodating creative knowledge. A literature review from a European perspective». Report 1. ACRE. Amsterdam: AMIDSt OCDE (2010). Program for International Student Assessment. OCDE, París.

Myro, R. (2011). "Crisis económica y modelo productivo». Información Comercial Española, 863, 79-94.

OCDE (2009). PISA ERA 2009. Resumen ejecutivo del informe español. Madrid: Ministerio de Educación.

Pareja-Eastaway, M. y SÁnchez-MartíneZ, M. T. (2011). «El alquiler: una asignatura pendiente en la política de vivienda en España». Ciudady Territorio. Estudios Territoriales, XLIII (167), 1-18. Ministerio de Fomento.

Pareja, M.; Turmo, J.; García, L.; Pradel, M. y Simo, M. (2008). «Main drivers for settlement in the Barcelona Metropolitan Region. The managers view». Acco- 
modating Creative Knowledge - Competitiveness of European Metropolitan Regions within the Enlarged Union. AMIDST, University of Amsterdam.

Pérez, F. y Robledo, J. C. (2010). "Cambios en el patrón de crecimiento de la economía española: 1970-2007». En: Coremberg, A. y Pérez, F. (eds.). Fuentes del crecimiento y productividad en Europa y América Latina. Bilbao: Fundación BBVA. P. 293-346.

Puig, A. (2011). «El modelo productivo español en el período expansivo de 19972007. Insostenibilidad y ausencia de políticas de cambio». Revista de Economía Critica 12, 64-81.

Sassen, S. (2001). The Global City. New York, London, Tokyo. Woodstock: Princeton University Press.

ScotT, A. y STORper, M. (2003). «Regions, Globalization, Development». Regional Studies, 37, 6-7, 549-78.

SERranO, L. (2010). "Capital humano y productividad: el caso de España». En: Coremberg, A. y Pérez, F. (eds.). Fuentes del crecimiento y productividad en Europa y América Latina. Bilbao: Fundación BBVA. P. 293-346.

Simmie, J. (2001). Innovative cities. Londres: Spon Press.

Sudrì̀, C. (2002). "Catalunya i Madrid. L'evolució en el llarg termini». El futur econòmic de Catalunya: lideratge econòmic i poder politic. Seminari d'economia del CCCB. Barcelona, juny de 2002. Barcelona: CCCB.

Torrent-Sellens, J.; Díaz-ChaO, A. y Ficapal-Cusí, P. (2009). «¿Sobreeducación o cambio estructural? Un análisis del impacto de las TIC, la formación universitaria y el cambio organizativo sobre los salarios en la empresa». Revista University Sociedad del Conocimiento (RUSC), 6 (2), 1-19. <http://rusc.uoc.edu>.

UNCTAD (2010). Creative Economy Report. Naciones Unidas.

VIVES, X. y TORRENS, L. (2004). Estratègies de les àrees metropolitanes europees davant l'ampliació de la Unió Europea. Barcelona: Ajuntament de Barcelona, Caixa Catalunya Obra Social, Pla Estratègic Metropolità de Barcelona, Iberia. Prospectiva, 2. 
Anexo 1. Índices de especialización productiva por CC. AA.

\begin{tabular}{|c|c|c|c|c|c|}
\hline Cod CNAE 09 & & CAT & MAD & VAL & PV \\
\hline & Producto Interior Bruto a precios de mercado & 18,54 & 17,80 & 9,69 & 6,12 \\
\hline $01-03$ & Agricultura, ganadería, silvicultura y pesca & 0,50 & 0,06 & 0,75 & 0,29 \\
\hline $10-33$ & Industria manufacturera & 1,34 & 0,59 & 1,08 & 1,74 \\
\hline $10-12$ & $\begin{array}{l}\text { Industria de la alimentación, fabricación de bebidas e industria } \\
\text { del tabaco }\end{array}$ & 1,16 & 0,33 & 1,01 & 0,68 \\
\hline $13-15$ & $\begin{array}{l}\text { Industria textil, confección de prendas de vestir e industria } \\
\text { del cuero y del calzado }\end{array}$ & 1,63 & 0,49 & 2,51 & 0,22 \\
\hline $16-18$ & $\begin{array}{l}\text { Industria de la madera y del corcho, industria del papel } \\
\text { y artes gráficas }\end{array}$ & 1,34 & 0,89 & 1,27 & 1,15 \\
\hline $19-21$ & $\begin{array}{l}\text { Coquerías y refino de petróleo; industria química; fabricación } \\
\text { de productos farmacéuticos }\end{array}$ & 2,31 & 0,86 & 0,78 & 0,93 \\
\hline $22-23$ & $\begin{array}{l}\text { Fabricación de productos de caucho y plásticos y de otros } \\
\text { productos minerales no metálicos }\end{array}$ & 0,98 & 0,44 & 1,78 & 1,61 \\
\hline $24-25$ & $\begin{array}{l}\text { Metalurgia y fabricación de productos metálicos, excepto } \\
\text { maquinaria y equipo }\end{array}$ & 1,08 & 0,43 & 0,63 & 3,59 \\
\hline $26-28$ & $\begin{array}{l}\text { Fabricación de productos informáticos, electrónicos y ópticos; } \\
\text { fabricación de material y equipo eléctrico; fabricación de } \\
\text { maquinaria y equipo n.c.o.p. }\end{array}$ & 1,44 & 0,77 & 0,80 & 2,94 \\
\hline $29-30$ & Fabricación de material de transporte & 1,19 & 0,71 & 0,78 & 1,89 \\
\hline $31-33$ & $\begin{array}{l}\text { Fabricación de muebles; otras industrias manufactureras } \\
\text { y reparación e instalación de maquinaria y equipo }\end{array}$ & 1,16 & 0,79 & 1,31 & 1,20 \\
\hline $41-43$ & Construcción & 0,87 & 0,84 & 1,15 & 0,94 \\
\hline $45-56$ & $\begin{array}{l}\text { Comercio al por mayor y al por menor; reparación de vehículos } \\
\text { de motor y motocicletas; transporte y almacenamiento; } \\
\text { hostelería }\end{array}$ & 1,07 & 1,02 & 1,06 & 0,89 \\
\hline $58-63$ & Información y comunicaciones & 0,94 & 2,42 & 0,59 & 0,79 \\
\hline $64-66$ & Actividades financieras y de seguros & 0,98 & 1,46 & 0,96 & 0,92 \\
\hline 68 & Actividades inmobiliarias & 0,99 & 0,68 & 1,23 & 0,76 \\
\hline $69-82$ & $\begin{array}{l}\text { Actividades profesionales, científicas y técnicas; actividades } \\
\text { administrativas y servicios auxiliares }\end{array}$ & 1,09 & 1,73 & 0,84 & 0,98 \\
\hline 84 & Administración pública y defensa; seguridad social obligatoria & 0,67 & 1,08 & 0,79 & 0,80 \\
\hline 85 & Educación & 0,88 & 0,75 & 1,03 & 1,00 \\
\hline $86-88$ & Actividades sanitarias y de servicios sociales & 0,87 & 0,83 & 0,89 & 1,01 \\
\hline $90-98$ & $\begin{array}{l}\text { Actividades artísticas, recreativas y de entretenimiento; } \\
\text { reparación de artículos de uso doméstico y otros servicios }\end{array}$ & 1,01 & 1,17 & 0,99 & 0,93 \\
\hline
\end{tabular}

Fuente: Elaboración propia a partir del INE. 
Anexo 2. Tasas de crecimiento del PIB y del VA por ramas de actividad

\begin{tabular}{|c|c|c|c|c|c|c|c|}
\hline & \multicolumn{3}{|c|}{ España } & \multicolumn{4}{|c|}{ Cataluña } \\
\hline & $08 / 00$ & $\begin{array}{c}09(\mathrm{P}) / \\
08(\mathrm{P})\end{array}$ & $\begin{array}{l}10(\mathrm{P}) / \\
09(\mathrm{P})\end{array}$ & $\begin{array}{l}11(\mathrm{E}) / \\
10(\mathrm{P})\end{array}$ & $08 / 00$ & $\begin{array}{l}09(\mathrm{P}) / \\
08(\mathrm{P})\end{array}$ & $\begin{array}{c}10(\mathrm{P}) / \\
09(\mathrm{P})\end{array}$ \\
\hline PIB a p.m. (en volumen) & 3,09 & $-3,7$ & $-0,1$ & 0,7 & 2,9 & $-3,7$ & 0,3 \\
\hline Agricultura, ganadería, silvicultura y pesca & $-0,54$ & $-1,4$ & $-1,1$ & 0,6 & 0,0 & $-0,5$ & $-2,0$ \\
\hline Industria manufacturera & 0,57 & $-12,2$ & 0,5 & 2,4 & 0,2 & $-11,0$ & 3,2 \\
\hline Alimentación, bebidas e industria del tabaco & 2,653 & $-2,2$ & & & 0,6 & $-1,9$ & \\
\hline $\begin{array}{l}\text { Textil, confección e industria del cuero } \\
\text { y del calzado }\end{array}$ & $-3,395$ & $-19,2$ & & & $-3,9$ & $-20,1$ & \\
\hline $\begin{array}{l}\text { Industria de la madera y del corcho, papel } \\
\text { y artes gráficas }\end{array}$ & 0,758 & $-14,1$ & & & 0,8 & $-13,9$ & \\
\hline $\begin{array}{l}\text { Refino de petróleo; industria química; productos } \\
\text { farmacéuticos }\end{array}$ & 0,72 & $-6,1$ & & & 1,5 & $-0,5$ & \\
\hline $\begin{array}{l}\text { Caucho y plásticos y otros productos minerales } \\
\text { no metálicos }\end{array}$ & 1,102 & $-18,6$ & & & 0,3 & $-18,5$ & \\
\hline $\begin{array}{l}\text { Mertalurgia y productos metálicos, excepto } \\
\text { maquinaria y equipo }\end{array}$ & 0,230 & $-20,8$ & & & 0,6 & $-21,8$ & \\
\hline $\begin{array}{l}\text { Ptos. informáticos, electrónicos y ópticos; material } \\
\text { y equipo eléctrico, maquinaria y equipo n.c.o.p. }\end{array}$ & $-1,199$ & $-13,1$ & & & $-0,5$ & $-13,5$ & \\
\hline Fabricación de material de transporte & $-1,208$ & $-11,2$ & & & 0,4 & $-17,7$ & \\
\hline $\begin{array}{l}\text { Fabricación de muebles; otras industrias } \\
\text { manufactureras y reparación e instalación } \\
\text { de maquinaria y equipo }\end{array}$ & 1,730 & $-8,4$ & & & $-0,5$ & $-3,2$ & \\
\hline Construcción & 4,32 & $-8,0$ & $-7,8$ & $-3,8$ & 4,6 & $-6,4$ & $-8,4$ \\
\hline $\begin{array}{l}\text { Comercio; reparación de vehículos; transporte } \\
\text { y almacenamiento; hostelería }\end{array}$ & 2,541 & $-2,4$ & 0,9 & 1,5 & & $-2,5$ & 0,5 \\
\hline Información y comunicaciones & 4,161 & $-1,2$ & 1,2 & 0,7 & 3,1 & $-3,5$ & 1,3 \\
\hline Actividades financieras y de seguros & 8,76 & $-3,8$ & 6,6 & $-1,0$ & 8,5 & $-2,9$ & 8,2 \\
\hline Actividades inmobiliarias & 2,601 & $-1,0$ & 1,5 & 1,1 & 3,4 & $-1,7$ & 1,1 \\
\hline $\begin{array}{l}\text { Actividades profesionales, científicas y técnicas; } \\
\text { actividades administrativas y servicios auxiliares }\end{array}$ & 4,36 & $-3,1$ & 0,4 & 2,5 & 3,4 & $-3,5$ & 1,1 \\
\hline Educación & 3,055 & & & & 3,8 & & \\
\hline Actividades sanitarias y de servicios sociales & 4,351 & & & & & & \\
\hline $\begin{array}{l}\text { Actividades artísticas, recreativas y de entretenimiento; } \\
\text { reparación de artículos de uso doméstico y otros servicios }\end{array}$ & 3,24 & $-0,3$ & $-3,2$ & $-1,8$ & & $-1,3$ & $-4,1$ \\
\hline
\end{tabular}

Referencias: P: estimación provisional; E: primera estimación.

Fuente: INE y elaboración propia. 


\begin{tabular}{|c|c|c|c|c|c|c|c|c|c|c|c|c|}
\hline \multicolumn{5}{|c|}{ Madrid } & \multicolumn{4}{|c|}{ Comunidad Valenciana } & \multicolumn{4}{|c|}{ País Vasco } \\
\hline $\begin{array}{c}11(\mathrm{E}) / \\
10(\mathrm{P})\end{array}$ & $08 / 00$ & $\begin{array}{c}09(\mathrm{P}) / \\
08(\mathrm{P})\end{array}$ & $\begin{array}{c}10(\mathrm{P}) / \\
09(\mathrm{P})\end{array}$ & $\begin{array}{c}11(\mathrm{E}) / \\
10(\mathrm{P})\end{array}$ & $08 / 00$ & $\begin{array}{c}09(\mathrm{P}) / \\
08(\mathrm{P})\end{array}$ & $\begin{array}{c}10(\mathrm{P}) / \\
09(\mathrm{P})\end{array}$ & $\begin{array}{c}11(\mathrm{E}) / \\
10(\mathrm{P})\end{array}$ & $08 / 00$ & $\begin{array}{c}09(\mathrm{P}) / \\
08(\mathrm{P})\end{array}$ & $\begin{array}{c}10(\mathrm{P}) / \\
09(\mathrm{P})\end{array}$ & $\begin{array}{l}11(\mathrm{E}) / \\
10(\mathrm{P})\end{array}$ \\
\hline 0,8 & 3,3 & $-2,7$ & 0,1 & 0,9 & 3,1 & $-5,9$ & $-0,6$ & 0,4 & 2,9 & $-4,1$ & 0,9 & 1,3 \\
\hline 0,9 & $-3,8$ & $-8,9$ & $-0,8$ & $-6,2$ & 0,3 & $-4,3$ & $-3,7$ & $-3,9$ & $-1,5$ & 1,4 & $-2,8$ & 0,6 \\
\hline \multirow[t]{10}{*}{2,5} & 0,2 & $-9,3$ & $-5,1$ & 3,8 & $-0,1$ & $-16,3$ & $-0,2$ & 1,7 & 1,8 & $-11,2$ & 1,9 & 2,9 \\
\hline & 1,1 & 3,1 & & & 1,2 & $-4,4$ & & & 1,4 & $-11,0$ & & \\
\hline & $-4,3$ & $-9,2$ & & & $-4,6$ & $-18,9$ & & & $-0,8$ & $-24,1$ & & \\
\hline & $-0,5$ & $-12,1$ & & & $-1,3$ & $-16,4$ & & & $-0,3$ & $-5,0$ & & \\
\hline & 1,3 & $-17,3$ & & & 1,9 & $-13,6$ & & & 1,0 & 37,3 & & \\
\hline & $-1,2$ & $-14,8$ & & & 0,3 & $-23,0$ & & & 2,6 & $-9,9$ & & \\
\hline & 2,2 & $-13,5$ & & & 2,2 & $-24,0$ & & & 1,2 & $-20,4$ & & \\
\hline & $-2,2$ & $-14,0$ & & & 0,8 & $-16,1$ & & & 2,7 & $-9,3$ & & \\
\hline & $-1,3$ & $-1,2$ & & & $-0,1$ & $-10,2$ & & & 2,9 & $-13,4$ & & \\
\hline & $-0,2$ & 3,5 & & & $-1,8$ & $-16,8$ & & & 1,3 & $-5,1$ & & \\
\hline$-3,6$ & 4,2 & $-6,5$ & $-8,8$ & $-1,6$ & 4,2 & $-10,0$ & $-8,9$ & $-4,7$ & 4,4 &,- 0 & $-4,4$ & $-1,7$ \\
\hline 1,8 & & $-1,8$ & 4,8 & $-0,5$ & & $-4,9$ & 0,7 & 2,2 & &,- 4 & 1,3 & 1,4 \\
\hline 2,0 & 3,3 & $-1,9$ & $-0,4$ & 1,6 & 2,1 & $-0,2$ & 1,6 & $-1,1$ & 3,3 & $-3,0$ & $-1,7$ & 1,7 \\
\hline$-5,5$ & 8,7 & $-3,4$ & 1,7 & 0,6 & 8,9 & $-4,0$ & 7,7 & 0,0 & 8,7 & $-3,7$ & 9,7 & 0,9 \\
\hline 1,1 & 3,3 & $-2,6$ & 0,8 & 2,8 & 4,3 & $-0,8$ & 1,4 & 0,9 & 3,5 & $-1,0$ & 1,7 & 1,1 \\
\hline 2,9 & 3,3 & $-1,7$ & 0,0 & 3,3 & 4,3 & $-8,0$ & 0,9 & 2,1 & 3,5 & 0,2 & 0,3 & 2,3 \\
\hline & 3,6 & & & & 4,3 & & & & 2,8 & & & \\
\hline
\end{tabular}

$\begin{array}{lllllllllllll}-1,7 & 1,7 & -2,5 & -1,5 & & -0,4 & -3,7 & -2,0 & & 1,8 & -2,8 & -1,4 \\ & & & & & & \end{array}$

